\title{
História termotectônica da margem continental brasileira a partir de dados de traços de fissão em apatita
}

\author{
(inclui material disponível digital)
}

\section{Christie Helouise ENGELMANN DE OLIVEIRA ${ }^{1}$ \& Andréa Ritter JELINEK ${ }^{2}$}

1 Programa de Pós-graduação em Geociências, Instituto de Geociências, Universidade Federal do Rio Grande do Sul. Av. Bento Gonçalves, 9.500, CEP 91.501-970, Porto Alegre, RS, Brasil (christie.oliveira10@gmail.com).

2 Instituto de Geociências, Universidade Federal do Rio Grande do Sul. Av. Bento Gonçalves, 9.500, CEP 91.501-970, Porto Alegre, RS, Brasil (andrea.jelinek@ufrgs.br).

Recebido em 11/2016. Aceito para publicação em 11/2017.

Versão online publicada em 16/3/2018 (www.pesquisasemgeociencias.ufrgs.br)

\begin{abstract}
Resumo - A margem continental brasileira denota estruturas geomorfológicas moldadas durante vários episódios de atividade tectônica iniciados no Neoproterozoico. Com o objetivo de estabelecer um modelo de história termotectônica para a margem continental brasileira, foi realizada a integração e reinterpretação dos dados traços de fissão em apatita (TFA) disponíveis ao longo de toda a margem continental. As idades TFA variam de 385-10 Ma. Os dados TFA revelam que a margem continental foi caracterizada por pelo menos três eventos térmicos após o Ciclo Brasiliano: Cretaceo Inferior, Cretaceo Superior e Paleógeno-Neógeno. Os eventos são relacionados aos processos de abertura do Oceano Atlântico Sul e às fases rifte e pós-rifte, com reativações tectônicas ao longo da margem. A Província Mantiqueira e o Cráton São Francisco registram os eventos mais antigos, desde o Ordoviciano e o Permiano, respectivamente, que afetaram de modo variado diferentes partes dessas províncias como reflexo das orogenias Famatiniana e Gondwanide.
\end{abstract}

Palavras-chave: Traços de fissão, rifte, resfriamento, soerguimento.

\begin{abstract}
THERMOTECTONIC HISTORY OF THE BRAZILIAN CONTINENTAL MARGIN FROM APATITE FISSION TRACK DATA. The Brazilian continental margin shows geomorphological structures formed during several episodes of tectonic activity initiated in the Neoproterozoic. In order to establish a thermotectonic history model for the Brazilian continental margin, an integration and reinterpretation of the apatite fission track (AFT) data was performed. AFT ages range from 385 to $10 \mathrm{Ma}$. The AFT data reveal that the continental margin was characterized by at least three thermal events post Brasiliano Cycle: Early Cretaceous, Late Cretaceous and Paleogene-Neogene. The events are related to the opening processes of the South Atlantic Ocean and to the rift and post-rift phases, with tectonic reactivations along to the margin. The Mantiqueira Province and the São Francisco Craton record the oldest events, from the Ordovician to the Permian, respectively, which affected the various parts in varying ways as evidence of the Famatinian and Gondwanide orogenies.
\end{abstract}

Keywords: Fission track, rift, cooling, uplift.

\section{Introdução}

A margem continental brasileira denota estruturas geomorfológicas moldadas durante vários episódios de atividade tectônica iniciados no Neoproterozoico, sendo sua topografia e relevo atuais semelhantes em muitos aspectos àqueles de outras margens continentais tipo rifte ao redor do globo terrestre (p. ex., Austrália, oeste da África, Noruega, Índia Ocidental). Ela faz parte do sistema de riftes do Atlântico Sul, originado pela separação do Gondwana Ocidental no Cretaceo Inferior, cuja abertura iniciou-se no sul e propagou-se ao norte ao longo de reativações tectônicas de antigos lineamentos (Nürnberg \& Müller, 1991; Meisling et al., 2001; Torsvik et al., 2009). A natureza da margem influenciou o desenvolvimento das bacias sedimentares offshore e das bacias intracontinentais, sendo que os sistemas de rifte Mesozoico-Cenozoico paralelos à costa estão presentes também offshore. A separação do paleocontinente em 130 Ma foi afetada por rifteamento generalizado e pelo vulcanismo da Província Paraná-Etendeka (Zalán et al., 1991; Macdonald et al., 2003). A atividade vulcânica relacionada à pluma causou a subida da crosta, incluindo a exposição do embasamento Pré-Cambriano, seguido de erosão e deposição.

Há mais de duas décadas, a evolução da história termotectônica da margem continental brasileira vem sendo estudada através da técnica TFA. 
O método termocronológico de baixa temperatura TFA é utilizado para determinar histórias térmicas da crosta superior terrestre ao longo do tempo (i.e., $<150{ }^{\circ} \mathrm{C}$ em escalas de tempo de $1-500 \mathrm{Ma}$; Gallagher \& Brown, 1997) e tem sido amplamente utilizado para entender o desenvolvimento de margens tipo rifte, quantificar taxas de exumação e denudação e fornecer idades e taxas de movimentação ao longo de falhas e zonas de cisalhamento (Gallagher \& Brown, 1999; Raab et al., 2005; Jelinek et al., 2014). 0 primeiro estudo com TFA no Brasil foi desenvolvido na margem sudeste por Gallagher et al. (1994), e os dados foram interpretados em termos de história térmica e denudação da margem.

Neste trabalho, é apresentada uma integração dos dados TFA disponíveis para a margem continental brasileira. Os dados foram interpretados no contexto de tectônica regional, resultando em uma história termotectônica da margem continental brasileira para temperaturas abaixo de $\sim 120^{\circ} \mathrm{C}$, em que os dados indicam que as idades TFA estão relacionadas aos eventos pré-, sin- e pós-rifte. Através do uso de uma plataforma de Sistema de Informação Geográfica e modelamento de dados, mostra-se como grandes conjuntos de dados regionais podem ser apresentados de maneira que seus padrões de variação possam ser facilmente compreendidos.

\section{2. Área, material e métodos}

\subsection{Contexto geológico}

A margem continental brasileira resulta da ruptura do paleocontinente Gondwana e está assentada sobre as rochas pré-rifte do embasamento que têm uma longa história geológica. 0 processo de ruptura do Gondwana Ocidental e consequente abertura do Atlântico Sul começou na parte do sul da América do Sul durante o Triássico Superior-Jurássico Inferior e propagou-se ao norte, alcançando a margem equatorial no Aptiano superior-Albiano inferior (Nürnberg \& Müller, 1991; Meisling et al., 2001; Torsvik et al., 2009). A abertura do Atlântico Sul foi precedida por volumoso magmatismo toleítico induzido pela Pluma Tristão da Cunha entre 145 e 130 Ma, originando a Província Paraná-Etendeka, localizada no sul da América do Sul e oeste da África (Zalán et al., 1991; Meisling et al., 2001; Macdonald et al., 2003).

As rochas do embasamento revelam uma segmentação ao longo da margem continental brasileira que reflete diferentes províncias estruturais
(Fig. 1). Essas províncias foram esboçadas pela primeira vez no trabalho de Almeida et al. (1981), com base na natureza do embasamento cristalino e da cobertura sedimentar. Recentemente, no contexto da colagem do Neoproterozoico, Brito Neves \& Fuck (2013) revisaram o conceito. A Província da Mantiqueira, situada ao longo da parte sul e sudeste da costa atlântica, ocupa a maior parte da margem, desde o estado do Rio Grande do Sul até parte do estado da Bahia, e é afetada principalmente pelo Ciclo Brasiliano. Na parte sudeste, na área da Bacia de Santos, onde a escarpa da margem tipo rifte é mais claramente expressa, esta província apresenta altitudes superiores a $1500 \mathrm{~m}$ (Serra do Mar e Serra da Mantiqueira).

O Cráton São Francisco, contíguo à parte noroeste do Cráton do Congo na África Ocidental antes da ruptura do Pangea (Neves, 2003), cobre quase todo o estado da Bahia e grande parte do estado de Minas Gerais, e é caracterizado por uma vasta planície interna e alguns platôs com elevações entre 500 e $1000 \mathrm{~m}$ na parte centro-leste (Almeida, 1977; Almeida et al., 1981). É constituído por rochas intensamente deformadas e metamorfizadas de idade Arqueana a Paleoproterozoica, sobrepostas pelos sedimentos plataformais Meso- e Neoproterozoicos dos supergrupos de Espinhaço e São Francisco e limitado por cinturões de dobramento Brasiliano Neoproterozoico desenvolvidos durante as orogenias colisionais que resultaram na formação do Gondwana Ocidental.

A Província da Borborema, localizada na margem nordeste brasileira, foi afetada pelo intensamente pelo Ciclo Brasiliano e é subdividida em três sub-províncias: Sul, Zona transversal (Central) e Norte, limitadas pelos importantes lineamentos brasilianos de Patos e Pernambuco (Neves, 2003; Van Schmus et al., 2011). A província é coberta a oeste por rochas sedimentares Fanerozoicas e vulcânicas da Bacia do Parnaíba, e ao norte e leste por depósitos costeiros Meso-Cenozoicos. O contexto geomorfológico da província não exibe alto topográficos próximo ao litoral, mas é caracterizado pelo Platô da Borborema, que se eleva da planície costeira até $\sim 1000 \mathrm{~m}$ ao norte do rio São Francisco, cuja origem epirogênica está relacionada com a ruptura do supercontinente Gondwana e ao magmatismo intraplaca Cenozoico (Lima et al., 2015).

A Bacia do Paraná é uma das maiores bacias intracratônicas brasileiras, cujo registro sedimentar compreende rochas formadas do período Ordoviciano ao Cretáceo, localizada na porção sudoeste do Supercontinente Gondwana durante o Fanerozoico (Milani, 1997). Seu relevo é constituído por altos planaltos $(\sim 1200 \mathrm{~m})$ e cuestas concêntricas 


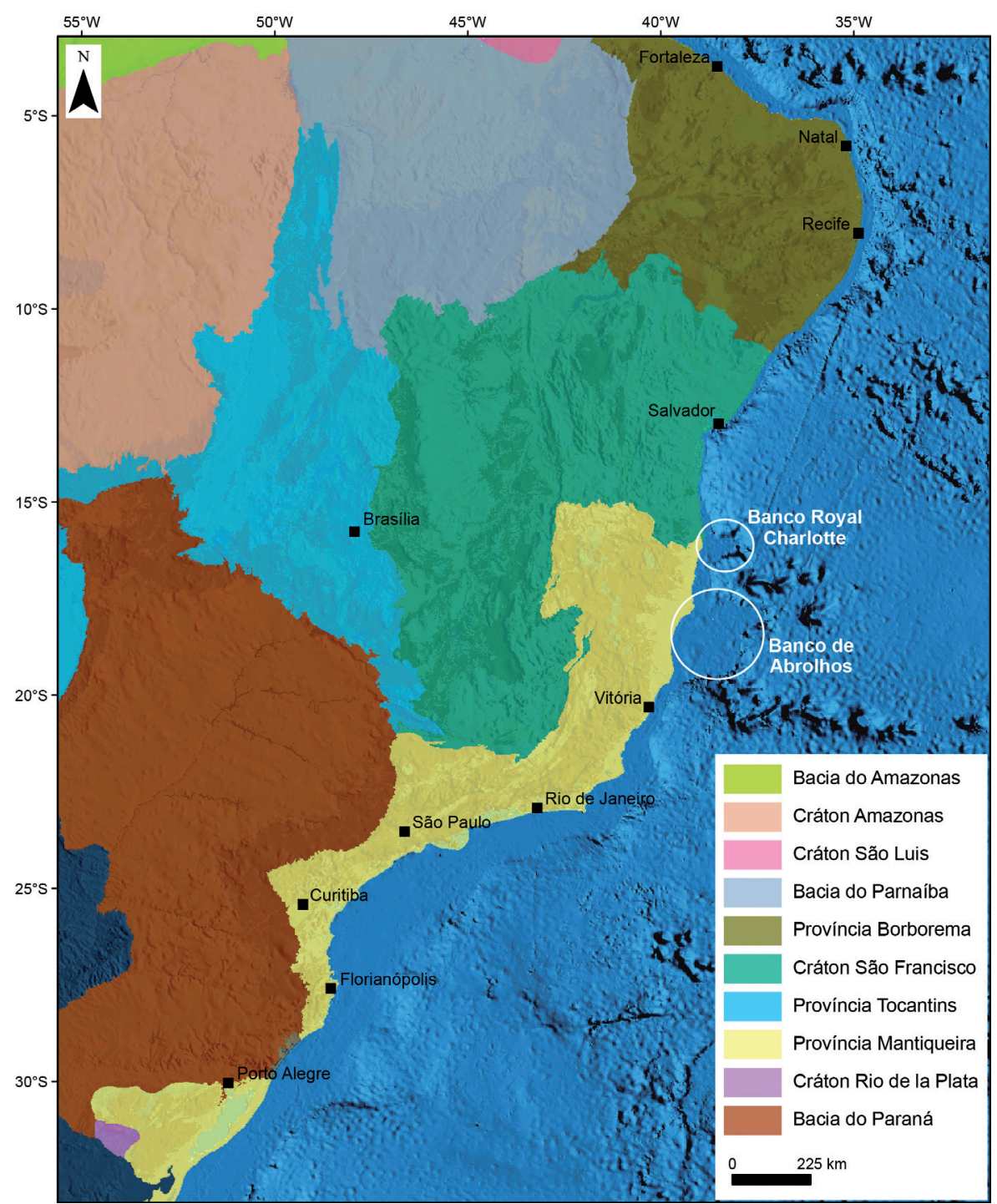

Figura 1. Mapa geotectônico das províncias da margem continental brasileira (Modificado de Brito Neves \& Fuck, 2013). Figure 1. Geotectonic provinces map of the Brazilian continental margin (Modified by Brito Neves \& Fuck, 2013).

drenados pelos rios Uruguai e Paraná. A presença dos maiores fluxos de lava basáltica da Província Paraná-Etendeka na crosta continental e dos milhares de corpos intrusivos de diabásio associados, evidenciam uma história térmica incomum que resultou na deformação dos estratos.

\subsection{Dados}

A base de dados utilizada foi constituída por uma série de dados publicados nos últimos 22 anos por diferentes autores (Fig. 2, 3, 4 e 5, Anexo 1), resultando em um total de 742 amostras com idades TFA e 592 comprimentos médios de traços (MTL). As altitudes registradas para cada amostra e os eventos termotectônicos obtidos em cada trabalho também foram utilizados no banco de dados para posterior correlação e interpretação (Anexo 1). Trabalhos com idades TFA aplicadas à datação de falhas e mineralização, sem localização das amostras ou com tabelas de idade TFA incompletas não foram utilizados no banco de dados. 0 conjunto de dados foi estruturado no programa ArcGis em um mesmo sistema de projeção e datum (UTM-WGS-84). Os mapas de contorno foram modelados utilizando o método de interpolação por Vizinho Natural (Natural Neighbor), que não confere tendências e trabalha igualmente bem com dados regularmente e irregularmente distribuídos. Nas figuras e mapas de contorno utilizou-se as idades centrais TFA.

\subsection{Método traços de fissão em apatita}

0 método TFA (Wagner \& Van den Haute, 1992; Gallagher et al., 1998; Donelick et al., 2005) baseia-se no fenômeno de que a fissão espontânea dos átomos de ${ }^{238} \mathrm{U}$ contido no retículo cristalino da apatita causa danos a este retículo (traços de fissão). Estes traços formam-se a uma taxa cons- 


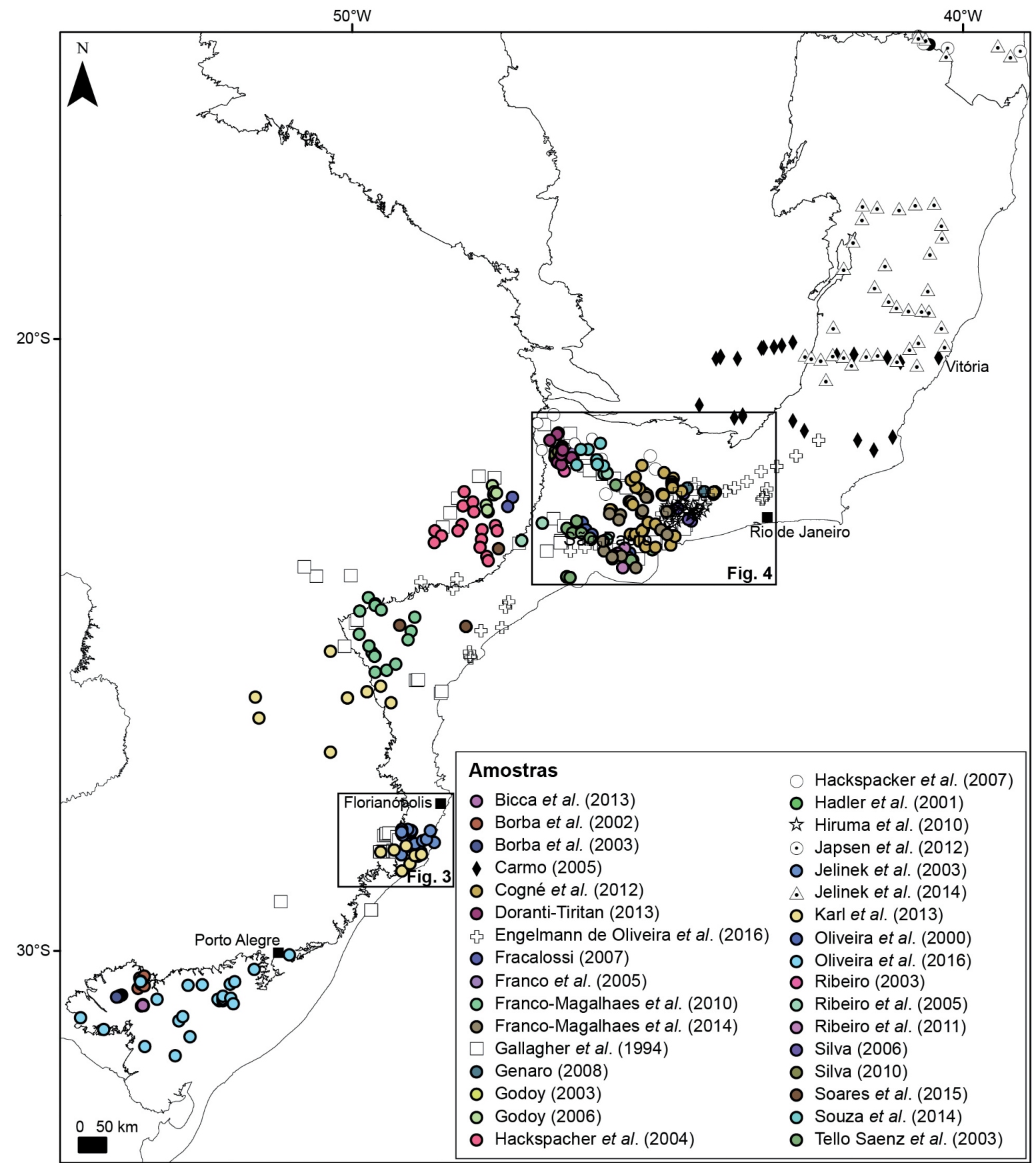

Figura 2. Mapa com a localização dos dados TFA publicados na margem sul, sudeste e leste do Brasil (Província Mantiqueira e Bacia do Paraná).

Figure 2. Location map of the published AFT data in the south, southeast and east Brazilian margin (Mantiqueira Province and Paraná Basin).

tante (segundo a lei exponencial), determinada pela constante de decaimento da fissão espontânea do ${ }^{238} \mathrm{U}$. 0 número de traços presentes num dado cristal de apatita depende tanto da concentração de urânio quanto do tempo que estes traços demoraram para se acumular. Através da contagem do número de traços que interceptam a superfície interna do cristal e do seu conteúdo de urânio, a idade traços de fissão pode ser calculada.

A temperatura afeta significativamente a quantidade e o comprimento dos traços de fissão. Quando os traços são submetidos a temperaturas superiores àquelas de bloqueio para um dado termocronômetro, aproximadamente $>60^{\circ} \mathrm{C}$ no caso do TFA, sofrem encurtamento e redução na densidade, processo este chamado de annealing (p. ex., Naeser \& Faul, 1969; Green et al., 1986; Laslett et al., 1987). Portanto, os dados de comprimento dos traços de fissão fornecem informações sobre as variações de temperatura experimentadas pela rocha hospedeira, enquanto a idade traços de fissão fornece informações sobre a duração dessas variações. A um elevado nível de annealing, acima de $\sim 120^{\circ} \mathrm{C}$ durante escalas de tempo geológico, todos 
os traços são apagados e os seus comprimentos e por Gleadow (1981), Green (1981), Laslett et al. idade traços de fissão são reduzidos a zero. Maio- (1987), Donelick et al. (2005), Tagami \& O'Sullivan res detalhes sobre o método TFA são apresentados (2005) e Jelinek et al. (2010).

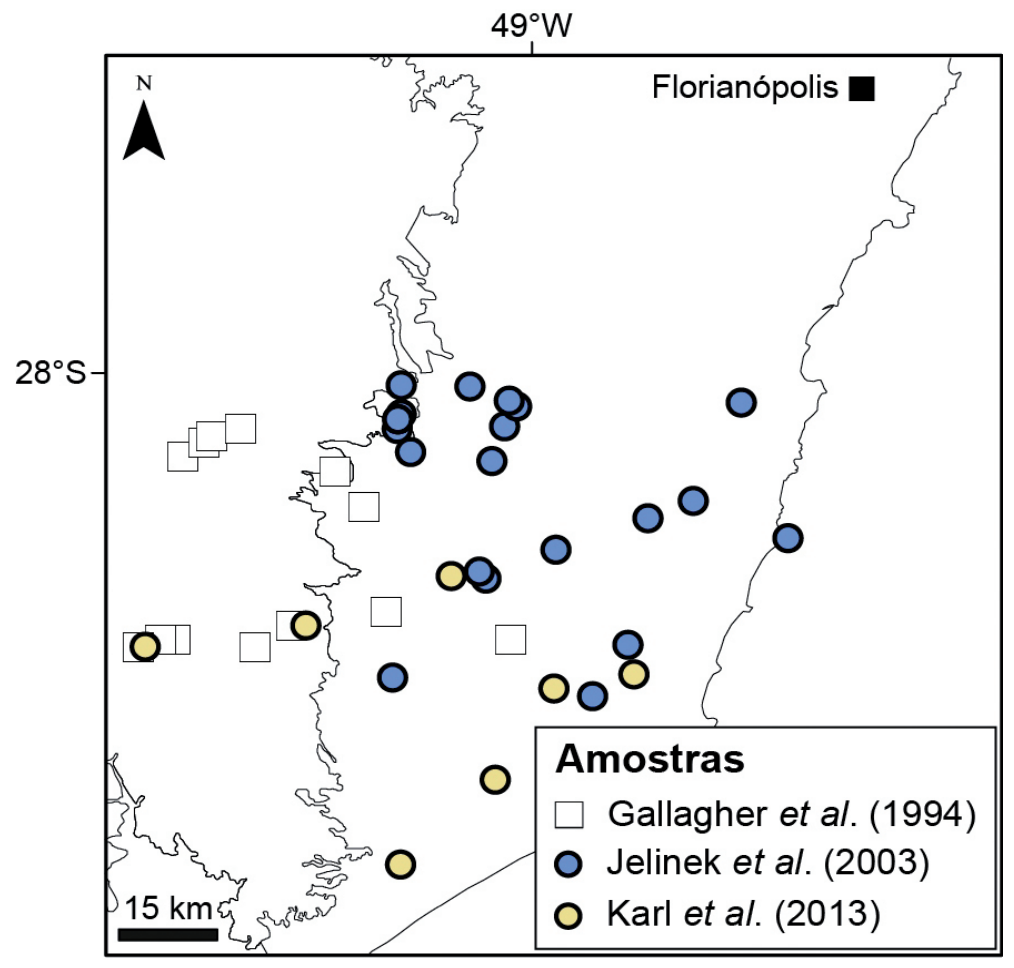

Figura 3. Mapa com a localização dos dados TFA publicados no sudeste do Estado de Santa Catarina (Província Mantiqueira e Bacia do Paraná).

Figure 3. Location map of the published AFT data in the southeast of the Santa Catarina state (Mantiqueira Province and Paraná Basin).

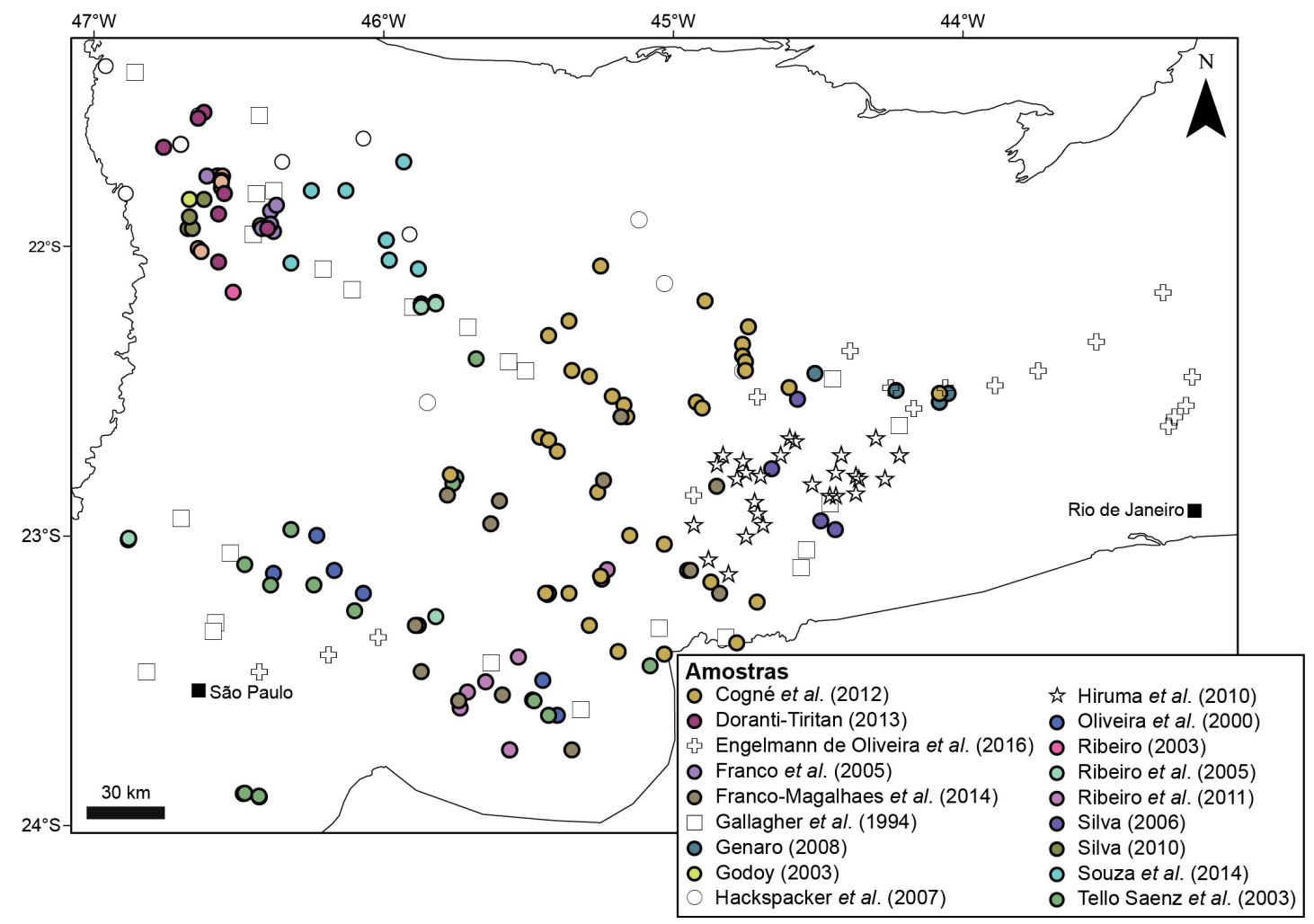

Figura 4. Mapa com a localização dos dados TFA publicados na margem brasileira entre os estados de São Paulo e Rio de Janeiro (Província Mantiqueira).

Figure 4. Location map of the published AFT data in the Brazilian margin between São Paulo and Rio de Janeiro states (Mantiqueira Province). 


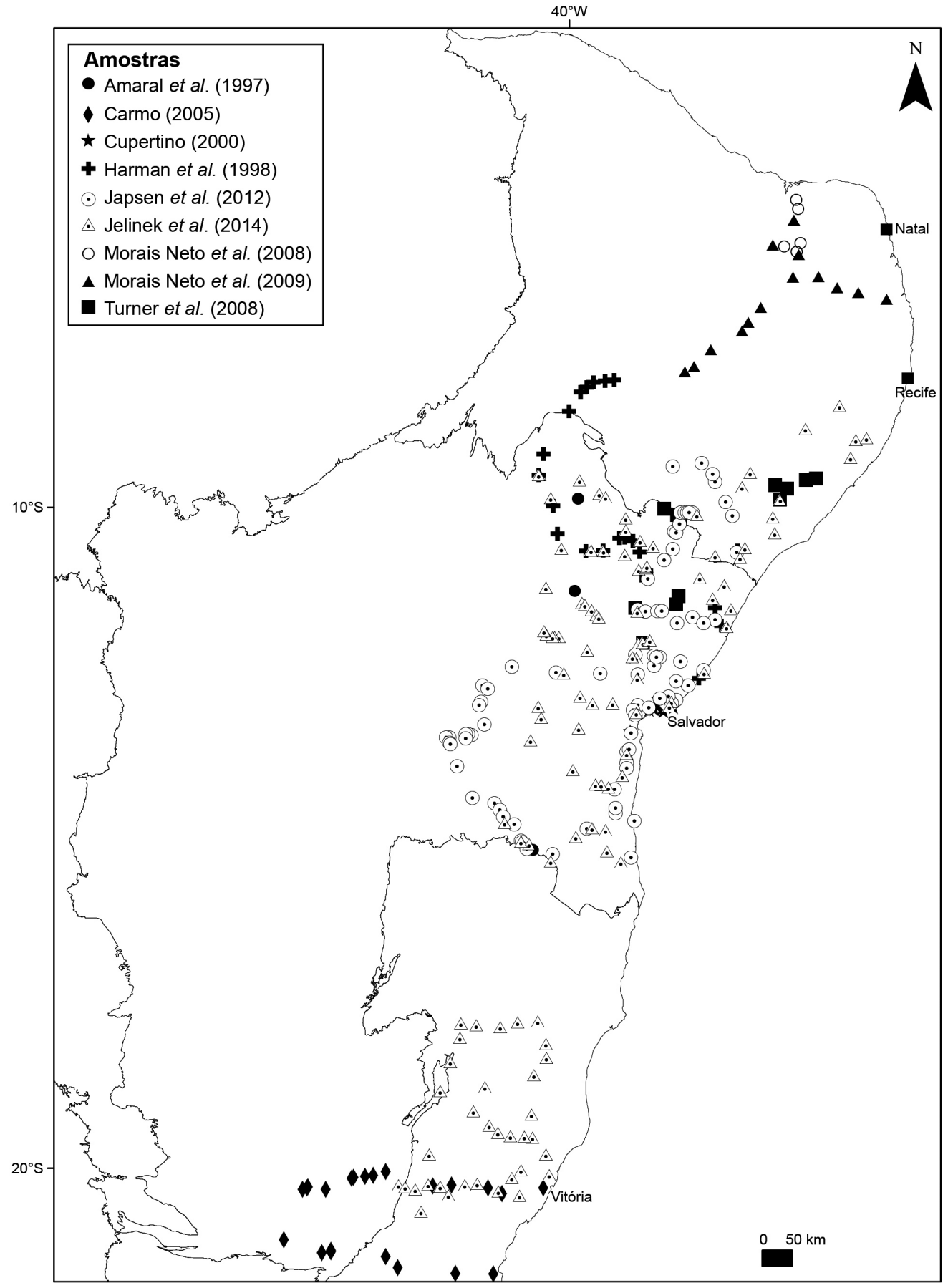

Figura 5. Mapa com a localização dos dados TFA publicados na região norte da Província Mantiqueira, cráton São Francisco e Província Borborema.

Figure 5. Location map of the published AFT data in the northern region of the Mantiqueira Province, San Francisco craton and Borborema Province.

\section{Resultados}

As idades TFA da margem continental brasileira variam de $\sim 385$ a $\sim 10$ Ma (Fig. 6), todas são consideravelmente mais jovens do que a idade de cristalização ou metamorfismo das rochas hospedeiras e tiveram um resfriamento monotônico como sugerido pelos autores dos 36 trabalhos compilados (Anexo 1). As figuras 6 e 7 mostram claramente que as idades TFA próximas à costa atual do sudeste e nordeste brasileiro são relati- vamente jovens (20-100 Ma) e consideravelmente mais jovens do que a idade da separação entre América do Sul e África. As idades TFA mais antigas do que a idade de ruptura do SW Gondwana ( $\sim 195 \mathrm{Ma}$ ) ocorrem somente nas partes interiores da margem continental, no extremo sul da Província Mantiqueira (estado do Rio Grande do Sul), e ao leste do Cráton São Francisco.

Em geral, não há uma clara relação entre a idade TFA e a altitude (Fig. 8). No entanto, as idades TFA >200 Ma tendem a estar associadas 


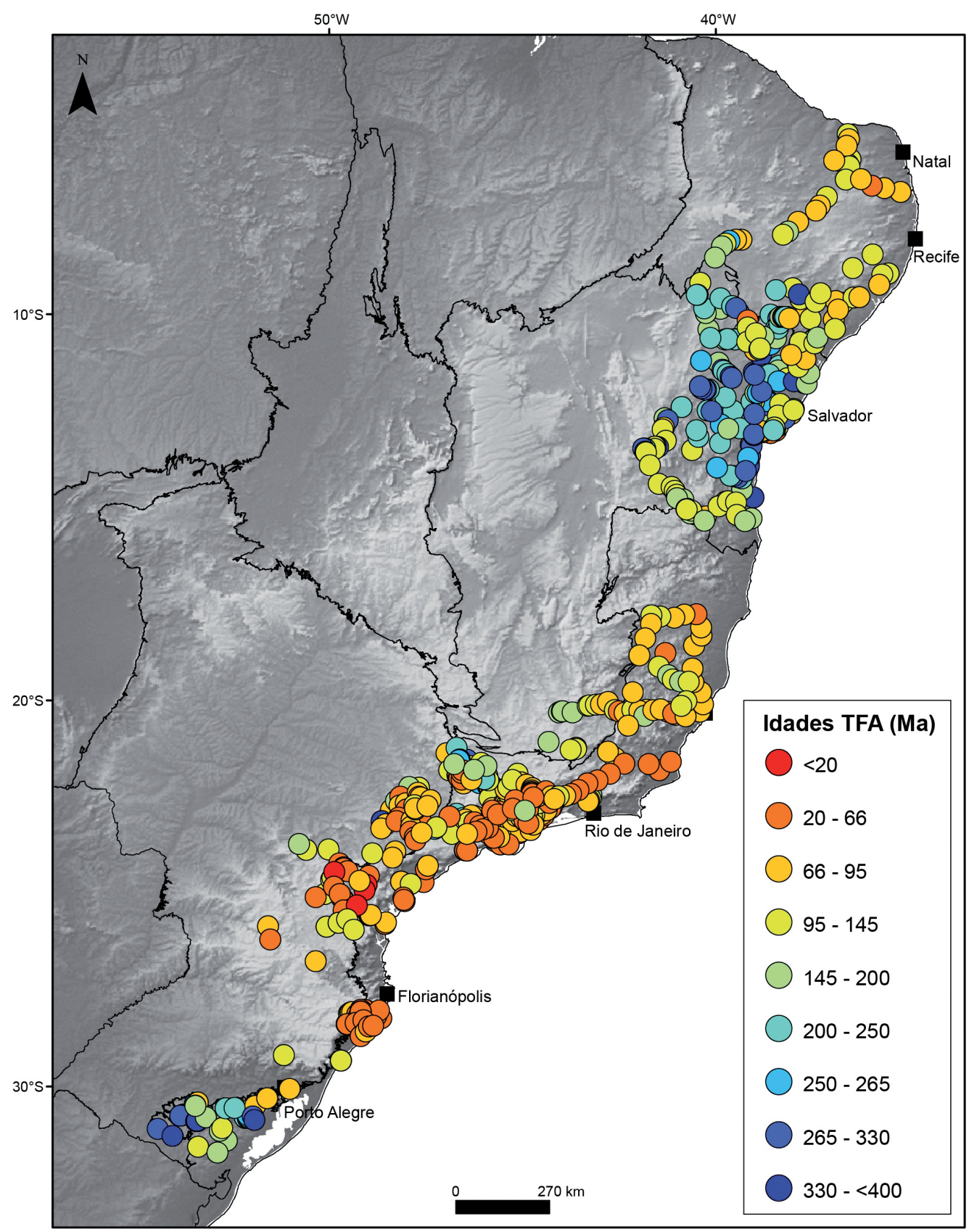

Figura 6. Mapa das idades TFA da margem continental brasileira. Figure 6. AFT age map for Brazilian continental margin.

a altitudes mais baixas $(<500 \mathrm{~m})$. A maioria das amostras com idade TFA do Cretaceo e Cenozoico apresentam MTL >11,5 $\mu \mathrm{m}$ (Fig. 9). Diversos autores (p. ex., Gallagher et al., 1994, Cogné et al., 2011) interpretaram a relação entre a idade TFA e o MTL na margem brasileira como um gráfico boomerang. Green (1986) demonstrou que esse padrão côncavo (concave-up) ocorre quando uma região experimenta uma fase de denudação acelerada, e é caracterizada por uma diminuição inicial nos MTL e idade, para um comprimento médio mínimo com idades intermediárias, seguido de um aumento progressivo nos MTL com idades sucessivamente mais jovens. No entanto, a relação entre as idades TFA e os MTL da margem brasileira (Fig. 9) não mostra um gráfico boomerang ideal, sugerindo uma complexa história térmica envolvendo vários episódios térmicos.

Todas as províncias estruturais (Fig. 10) apresentam longos MTL e idades AFT associadas com a separação continental entre América do Sul e África ( 135-95 Ma), relacionados ao episódio de resfriamento e denudação que levou à formação dessas margens. Outro episódio de resfriamento, exceto para a Bacia do Paraná, pode ser inferido durante o magmatismo do Cretaceo Superior e do Paleógeno (Fig. 10A, 10B e 10C), e indica que as amostras que apresentam longos MTL resfriaram rapidamente a partir de temperaturas de $\sim 120^{\circ} \mathrm{C}$ no momento indicado pela idade TFA. 


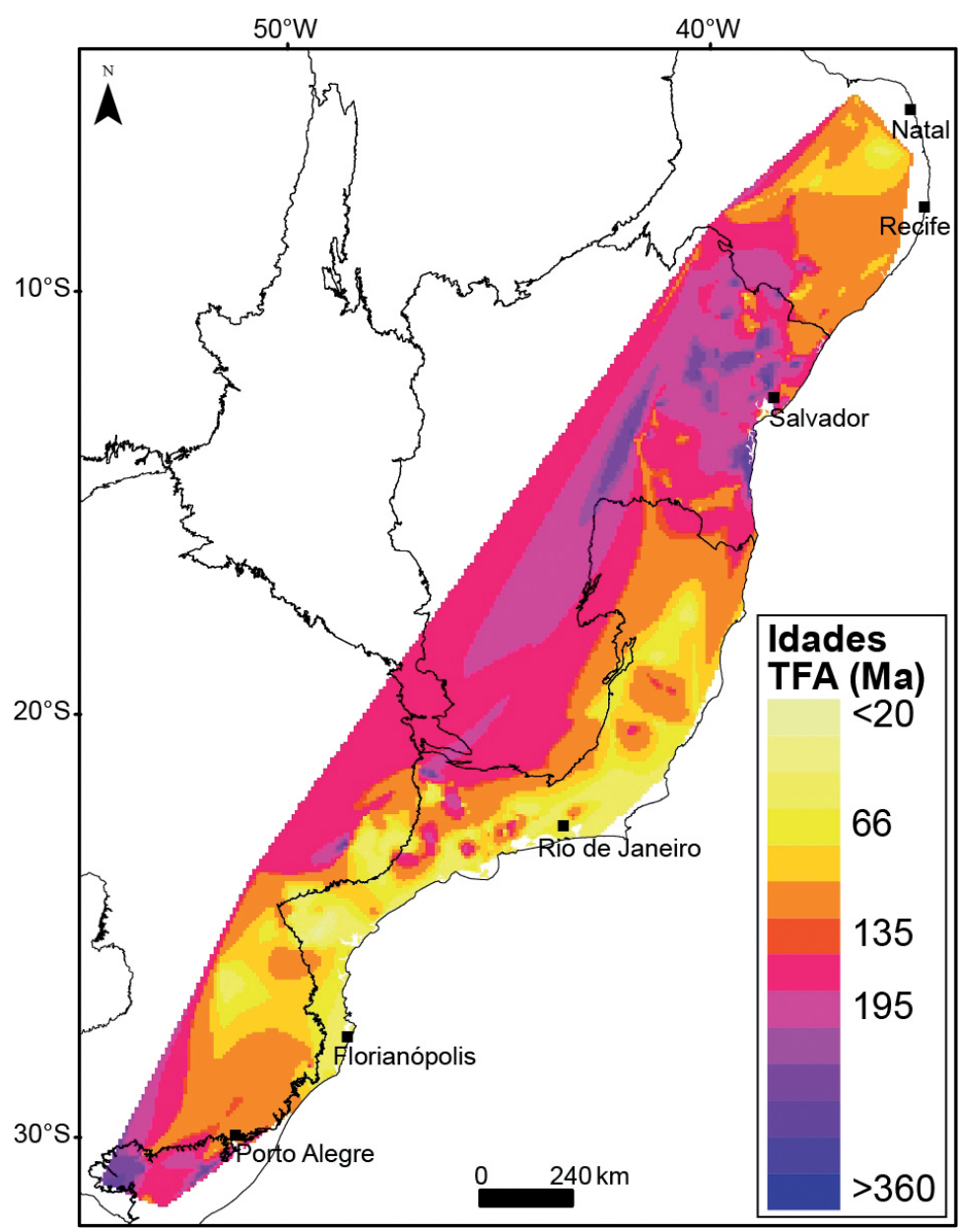

Figura 7. Mapa de contorno das idades TFA ao longo da margem continental brasileira. Figure 7. Contour map of AFT ages across the Brazilian continental margin.

A Bacia do Paraná registra apenas idades após a ruptura do SW Gondwana (Fig. 10D), com a maioria das idades datando do magmatismo Paraná-Etendeka, como consequência da influência térmica e total annealing em termos de idades traços de fissão. As distribuições dos MTL nas amostras desta província são particularmente curtos $(<12 \mu \mathrm{m}$, Fig. 10D) nas idades TFA mais jovens. Tais distribuições de MTL podem ser qualitativamente interpretadas em termos de arrefecimento prolongado, como consequência da lenta denudação ocorrida após a ruptura.

\section{Discussão dos resultados}

Dados TFA fornecem importantes informações termotectônicas dos eventos ocorridos ao longo dos últimos 500 Ma na história geológica. Em escala regional, a resposta geomorfológica aos processos de rifteamento e ruptura continental, indicada pela cronologia, variou significativamente ao longo da margem continental brasileira (Fig. 6 e 7, Anexo 1). Os dados TFA mostram que o desenvolvimento pós Ciclo Brasiliano da margem brasileira foi caracterizado por pelo menos três eventos térmicos: Cretaceo Inferior, Cretaceo Superior e Paleógeno-Neógeno. Somente a Província Mantiqueira e o Cráton São Francisco registram idades TFA e eventos mais antigos, desde o Ordoviciano e o Permiano, respectivamente, que afetaram de modo variado diferentes partes dessas províncias.

Na margem extremo sul da Província Mantiqueira (estado do Rio Grande do Sul), as antigas idades TFA estão relacionadas ao resfriamento contínuo e relativamente lento desde o Paleozoico (Ordoviciano ao Permiano), e refletem o possível soerguimento da área em resposta à colisão entre o terreno Precordillera e o Cráton Rio de la Plata, na margem oeste do Gondwana Ocidental durante as orogenias Famatiniana e Gondwanide (Oliveira et al., 2016). Esta parte da margem brasileira é caracterizada por uma topografia relativamente baixa e uma grande planície costeira, não apresentando uma característica morfológica de margem continental passiva. De modo contrário, a margem continental sudeste e leste brasileira, parte da Província Mantiqueira, apresenta uma morfologia de margem continental passiva característica, com as bacias sedimentares offshore (bacias de Santos, Campos e Espírito Santo) separadas da região 
continental elevada (Serra do Mar e Serra da Mantiqueira) por uma planície costeira relativamente estreita (Gallagher et al., 1994). As idades TFA refletem esta morfologia de margem passiva, com um aumento das idades de 40-90 Ma na planície costeira para $>300$ Ma no interior continental, configurando uma maior denudação na planície, como sugerido por diversos autores (p. ex., Gallagher et al., 1994, 1995; Gallagher \& Brown, 1999; Carmo, 2005; Hiruma et al., 2010; Engelmann de Oliveira et al., 2016).

Os dados da região sudeste do Brasil também apresentam idades significativamente mais jovens do que a idade do rifteamento que levou à formação da margem continental (Fig. 6 e 10). Para a maior parte da margem, e por grande parte dos autores relacionados (Fig. 2, 3, 4 e 5, Anexo 1), o resfriamento relativamente rápido durante o $\mathrm{Pa}$ leógeno-Neógeno é interpretado como resultado de episódios de aumento nas taxas de denudação relacionados à formação e reativação de blocos de falha de alto ângulo que se moveram em resposta às tensões intraplaca. Os episódios de denudação também são contemporâneos à deposição de rochas sedimentares clásticas nas bacias da margem sudeste brasileira. Diversos autores (p. ex., Gallagher et al., 1994, 1995; Hiruma et al., 2010; Jelinek et al., 2014; Engelmann de Oliveira et al., 2016) discutem que as altas taxas de denudação pós-rifte indicadas para a margem, provavelmente refletem a geometria e o momento da reativação tectônica pós-rifte de estruturas intracontinentais maiores, e as taxas de denudação são correlacionáveis às espessuras do registro sedimentar offshore nas bacias de Santos e Espírito Santo.

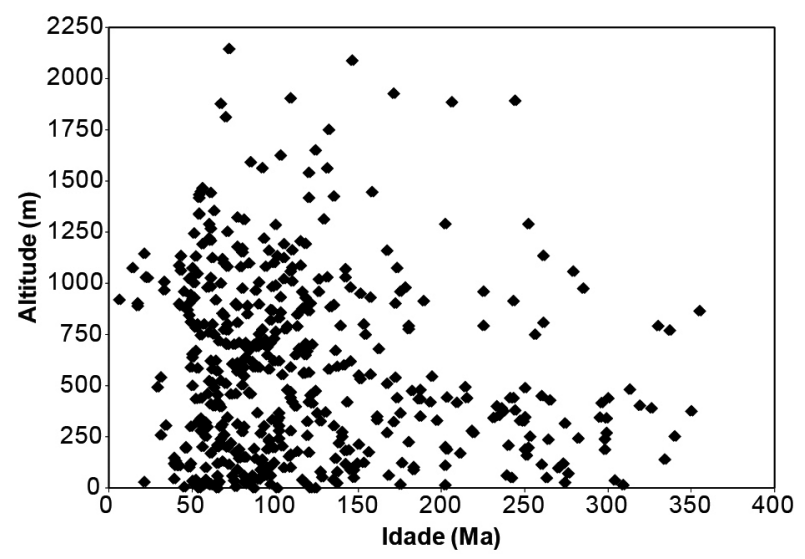

Figura 8. Relação entre as idades TFA e a altitude das amostras.

Figure 8. Relationship between AFT ages and elevation of the samples.

O Arco de Ponta Grossa, na região de Curitiba, apresenta as idades TFA mais jovens de toda a margem continental (Fig. 4; Franco-Magalhaes et al., 2010). A região é um alto topográfico caracterizado por um grande número de diques associados ao magmatismo Paraná-Etendeka e limitado por zonas de cisalhamento NW-SE (Zalán et al., 1990). Segundo Gallagher et al. (1994), as amostras presentes nesta região sofreram annealing total em termos de idade de traços de fissão, como consequência da influência térmica do magmatismo a aproximadamente $130 \mathrm{Ma}$. No entanto, isso teria sido efetivamente instantâneo e seria esperado que todas as idades TFA fossem semelhantes à idade do magmatismo. Desta forma, Franco-Magalhaes et al. (2010) atribuem as idades mais jovens (<20 Ma) à reativação das zonas de cisalhamento do Pré-Cambriano e ao soerguimento/exumação da área, levando à formação de bacias terciarias. A reativação tectônica Cenozoica do embasamento continental e consequente formação de Riftes Cenozoicos também é sugerido por outros autores na margem sudeste (p. ex., Hiruma et al., 2010; Cogné et al., 2012; Karl et al., 2013; Engelmann de Oliveira et al., 2016).

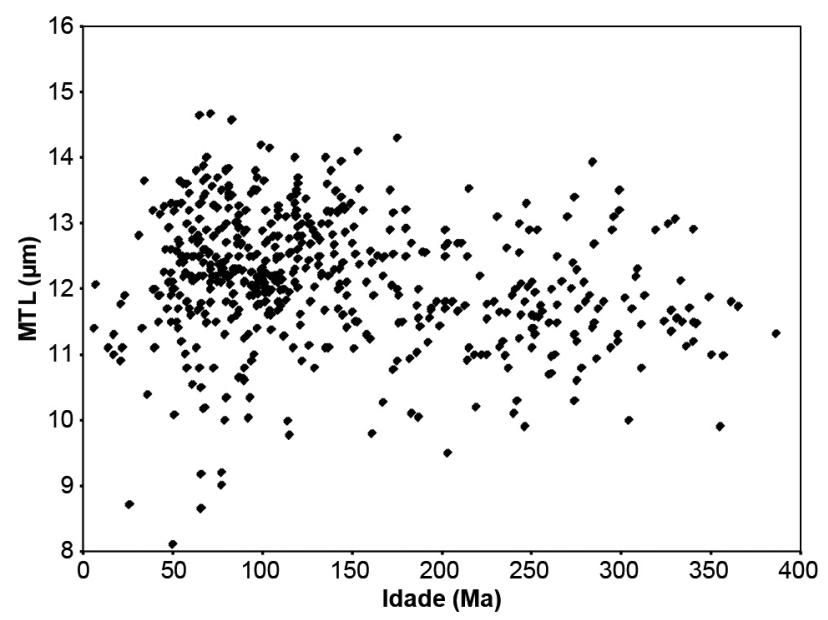

Figura 9. Relação entre as idades TFA e os MTL para todo o conjunto de dados.

Figure 9. Relationship between AFT ages and MTL for the entire dataset.

Ao contrário da margem sudeste, a margem nordeste, na região do Cráton São Francisco, registra idades TFA mais antigas e um episódio térmico durante o Permiano e Jurássico Inferior, reflexo da Orogenia Gondwanide como sugerido por Jelinek et al. (2014). Esta região é típica da região semi-árida do nordeste caracterizada como um pediplano, com relevo monótono, vales estreitos e vertentes dissecadas, conhecida como Depressão Sertaneja. Os modelos de história térmica apresentados por Jelinek et al. (2014) não mostram evidência de resfriamento significativo durante a formação das bacias de margem passiva nesta região, o que implica que a área não foi significativamente afetada pelos processos tectônicos e térmicos relacionados ao 
rifteamento, refletindo também nas idades TFA que são na grande maioria pré-rifte. Os modelos e idades TFA são apoiados pela evolução das bacias do nordeste, que apresentam fases essencialmente não-magmáticas pré-rifte e rifte (Chang et al., 1992). 0 magmatismo nesta parte da margem está registrado ao sul (banco de Abrolhos e Royal
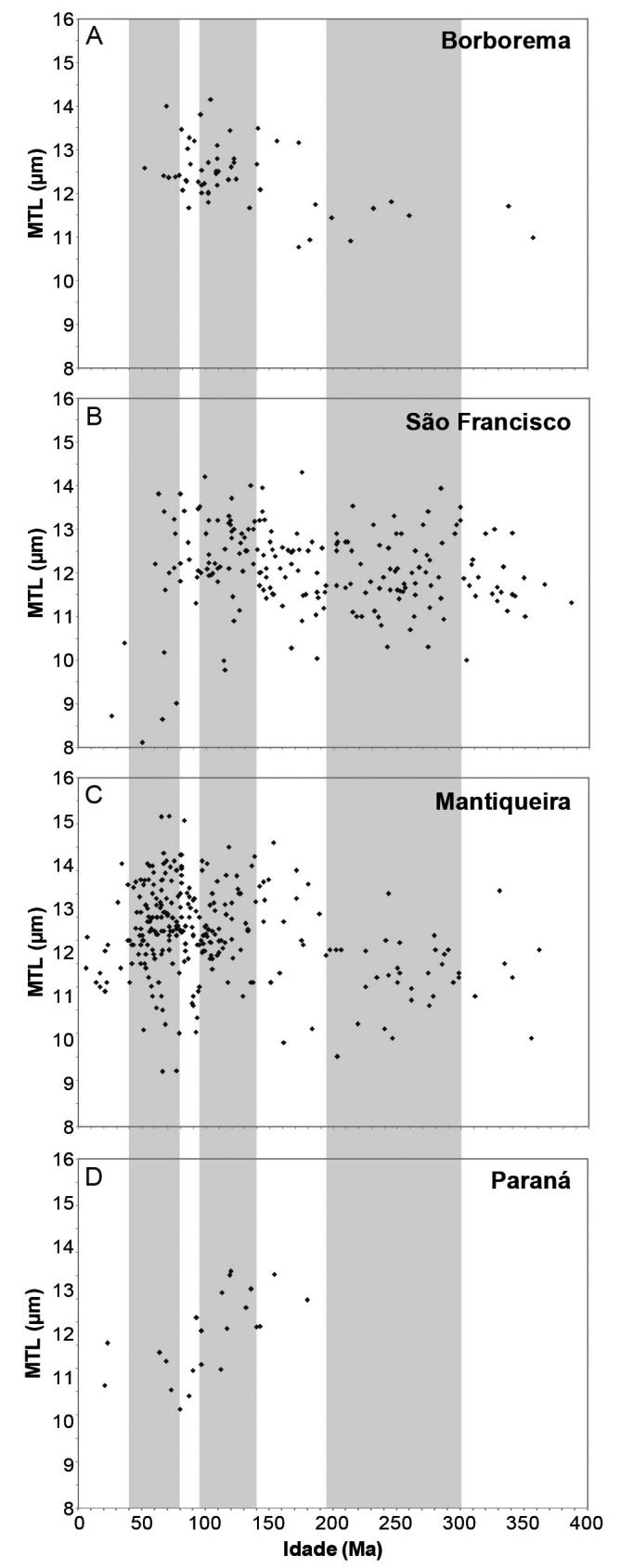

Figura 10. Relação entre as idades TFA e os MTL para as amostras da Província Borborema (A), Cráton São Francisco (B), Província Mantiqueira (C) e Bacia do Paraná (D). As três faixas sombreadas indicam o tempo aproximado antes da ruptura do SW Gondwana (cerca de $195 \mathrm{Ma}$ ), o intervalo de tempo da separação entre América do Sul e África (135-95 Ma) e o magmatismo do Cretaceo Superior e Paleógeno (80-40 Ma). Figure 10. Relationship between AFT ages and MTL for the samples from Borborema Province (A), São Francisco craton (B), Mantiqueira Province (C) and Paraná Basin (D). The three shaded bands indicate the approximate time before of SW Gondwana breakup (ca. 195 Ma), the spread time of South America and Africa breakup (135-95 Ma) and the Late Cretaceous and Paleogene magmatism (80-40 Ma).
Charlotte, Fig. 1) e ocorreu durante o estágio pós-rifte, entre 60 e $40 \mathrm{Ma}$, relacionado ao movimento da placa Sul-Americana sobre hotspots (Chang et al., 1992; Mizusaki et al., 2002).

As idades TFA da Província Borborema são claramente mais jovens que as idades do CrátonSão Francisco, sendo que a maior parte é relacionada ao evento termotectônico do Cretaceo (Anexo 1), correspondente à abertura do Oceano Atlântico Sul. Lima et al. (2015), utilizando métodos sísmicos, sugerem que o soerguimento do Platô Borborema foi causado por desequilíbrio térmico na crosta durante a ruptura do Gondwana e abertura do Oceano Atlântico Sul, no Cretaceo. 0 desequilíbrio térmico e o magmatismo sin- e pós-rifte (60-40 Ma) presentes ao longo da margem equatorial brasileira, na Província Borborema (Mizusaki et al., 2002), influenciaram a evolução dessa margem e registraram esses eventos nas idades TFA (Fig. 2 e 10), com algumas idades TFA datando o magmatismo devido à sua influência térmica. Porém, de acordo com os dados TFA, o maior estresse térmico na região foi durante a separação entre América do Sul e África (135-95 Ma).

Esse padrão de idades TFA e de eventos térmicos ao longo da margem continental brasileira não está apenas relacionado ao processo de rifteamento, mas envolve outros processos importantes como: (i) soerguimento isostático em resposta à denudação da margem continental e sedimentação nas bacias onshore e offshore, sugeridos e detalhados por Gilchrist \& Summerfield (1994) e Gallagher et al. (1994); e, (ii) magmatismo pós-rift e reativação tectônica das principais estruturas intracontinentais, que ocasionaram uma denudação localmente acelerada sobreposta ao padrão regional secular (Gallagher \& Brown, 1999; Cobbold et al., 2001). O soerguimento isostático seguido de sedimentação nas bacias é mais evidente na margem sudeste, Província Mantiqueira, com a ocorrência das serras do Mar e da Mantiqueira e de diversas bacias terciarias onshore e bacias offshore. Na Província da Borborema e na região do Arco de Ponta Grossa, o soerguimento foi causado por desequilíbrio térmico devido ao magmatismo e reativação tectônica com geração de bacias onshore.

\section{Conclusões}

Os dados TFA discutidos por diferentes autores ao longo dos anos e integrados neste trabalho, permitiram estabelecer um modelo de história termotectônica para a margem continental brasileira, que é complexo e reflete controles litológicos e estruturais. 
As idades TFA variam de $\sim 385-10$ Ma e todas são consideravelmente mais jovens do que a idade de cristalização ou metamorfismo de suas rochas hospedeiras. A presença de um grande número de amostras com idades entre 135 e 66 Ma é relacionada à separação continental e subsequente magmatismo e reativações tectônicas do Cretaceo Superior ao Paleógeno.

Os dados TFA da margem continental sudeste brasileira mostram uma tendência geral semelhante à observada em outras margens do tipo rifte, com idades mais jovens em direção à costa. A maioria das idades TFA da Província Borborema está relacionada ao evento térmico do Cretaceo, associado à abertura do Oceano Atlântico Sul.

A Província Mantiqueira e o cráton São Francisco registram os eventos térmicos mais antigos, desde o Ordoviciano e o Permiano, respectivamente, que afetaram de modo variado diferentes partes destas províncias e refletem as orogenias $\mathrm{Fa}-$ matiniana e Gondwanide.

Agradecimentos - Este estudo constitui parte da tese de doutorado da primeira autora junto ao Programa de Pós-graduação em Geociências da UFRGS. Andréa R. Jelinek é bolsista de produtividade do CNPq.

\section{Referências}

Almeida, F.F.M. 1977. 0 Cráton do São Francisco. Revista Brasileira de Geociências, 7: 349-364.

Almeida, F.F.M., Hasui, Y., Brito Neves, B.B. \& Fuck, R.A. 1981. Brazilian structural provinces: an introduction. Earth-Science Reviews, 17(1-2): 1-29.

Amaral, G., Born, H., Hadler, J.C.N., Iunes, P.J., Kawashita, K., Machado Jr., D.L., Oliveira, E.P., Paulo, S.R. \& Tello, C.A.S. 1997. Fission track analysis of apatites from Sao Francisco craton and Mesozoic alcaline-carbonatite complexes from central and southeastern Brazil. Journal of South American Earth Sciences, 10(3): 285-294.

Bicca, M.M., Chemale Jr., F., Jelinek, A.R., Oliveira, C.H.E., Guadagnin, F. \& Armstrong, R. 2013. Tectonic evolution and provenance of the Santa Bárbara Group, Camaquã Mines region, Rio Grande do Sul, Brazil. Journal of South American Earth Sciences, 48: 173-192.

Borba, A.W., Lima, E.F., Vignol-Lelarge, M.L.M., Mizusaki, A.M.P., Sparrenberg, I. \& Barros, C.E. 2003. Significance of Late Paleozoic Fission-track Ages in Volcanic Rocks from the Lavras Do Sul Region, Southernmost Brazil. Gondwana Research, 6: 79-88.

Borba, A.W., Vignol-Lelarge, M.L.M. \& Mizusaki, A.M.P. 2002. Uplift and denudation of the Caçapava do Sulgranitoids (southern Brazil) during Late Paleozoic and Mesozoic: constraints from apatite fission-track data. Journal of South American Earth Sciences, 15: 683-692.

Brito Neves, B.B. \& Fuck, R.A. 2013. Neoproterozoic evolution of the basement of the South-American plat- form. Journal of South American Earth Sciences, 47: 72-89.

Carmo, I.0. 2005. Geocronologia do Intemperismo Cenozóico no Sudeste do Brasil. Rio de Janeiro, 134p. Tese de Doutorado, Programa de Pós-Graduação em Geologia, Universidade Federal do Rio de Janeiro.

Chang, H.K., Kowsmann, R.O., Figueiredo, A.M.F. \& Bender, A. 1992. Tectonics and stratigraphy of the East Brazil Rift system: an overview. Tectonophysics, 213(1): 97-138.

Cobbold, P.R., Meisling, K.E. \& Mount, V.S. 2001. Reactivation of an obliquely rifted margin, Campos and Santos basins, southeastern Brazil. AAPG Bulletin, 85 (11): 1925-1944.

Cogné, N., Gallagher, K., \& Cobbold, P.R. 2011. Post-rift reactivation of the onshore margin of southeast Brazil: evidence from apatite (U-Th)/He and fission-track data. Earth and Planetary Science Letters, 309(1): 118-130.

Cogné, N., Gallagher, K., Cobbold, P.R., Riccomini, C. \& Gautheron, C. 2012. Post-breakup tectonics in southeast Brazil from thermochronological data and combined inverse-forward thermal history modeling. Journal of Geophysical Research, 117: B11413.

Cupertino, J.A. 2000. Evolução tectono-climática na fase Rifte das bacias de Camamu, parte norte, e sul do Recôncavo, com ênfase na utilização de isótopos estáveis e traços de fissão. Porto Alegre. Tese de Doutorado, Programa de Pós-graduação em Geociências, Instituto de Geociências, Universidade Federal do Rio Grande do Sul.

Donelick, R.A., O'Sullivan, P.B. \& Ketcham, R.A. 2005. Apatite Fission-Track Analysis. In: Reiners, P.W., Ehlers, T.A. (Ed.). Low-Temperature Thermochronology: Techniques, Interpretations, and Applications. Washington: Mineralogical Society of America, Reviews in Mineralogy and Geochemistry, 58: 49-94.

Doranti-Tiritan, C. 2013. Evolução Geomórfica e Modelagem Termocinemática 3D da Região do Maciço Alcalino de Poços de Caldas (SP/MG). Rio Claro, 160p. Tese de Doutorado, Programa de Pós-Graduação em Geologia Regional, Instituto de Geociências e Ciências Exatas, Universidade Estadual Paulista.

Engelmann de Oliveira, C.H.E., Jelinek, A.R., Chemale, F. \& Cupertino, J.A. 2016. Thermotectonic history of the southeastern Brazilian margin: Evidence from apatite fission track data of the offshore Santos Basin and continental basement. Tectonophysics, 685: 21-34.

Fracalossi, C.P. 2007. Uso da termocronologia por traços de fissão em apatita no reconhecimento de áreas de recarga e análises isotópicas de ${ }^{234} \mathrm{U} /{ }^{238} \mathrm{U}$ em águas subterrâneas do aquífero Itararé no município de Americana (SP). Rio Claro, 81p. Dissertação de Mestrado, Instituto de Geociências e Ciências Exatas, Universidade Estadual Paulista.

Franco, A.O., Hackspacher, P.C., Godoy, D.F., Ribeiro, L.F.B. \& Guedes, S. 2005. História Térmica do Maciço Alcalino de Poços de Caldas (SP/MP) e Adjacências Através da Análise de Datação Por Traços de Fissão em Apatitas. Revista Brasileira de Geociências, 35(3): 
351-358.

Franco-Magalhaes, A.O., Hackspacher, P.C., Glasmacher, U.A. \& Saad, A.R. 2010. Rift to post-rift evolution of a "passive" continental margin: the Ponta Grossa Arch, SE Brazil. International Journal of Earth Sciences, 99(7): 1599-1613.

Franco-Magalhaes, A.O.B., Cuglieri, M.A.A., Hackspacher, P.C. \& Saad, A.R. 2014. Long-term landscape evolution and post-rift reactivation in the southeastern Brazilian passive continental margin: Taubaté basin. International Journal of Earth Sciences, 103(2): 441453.

Gallagher, K. \& Brown, R. 1997. The onshore record of passive margin evolution. Journal of the Geological Society, 154(3): 451-457.

Gallagher, K. \& Brown, R. 1999. The Mesozoic denudation history of the Atlantic margins of southern Africa and southeast Brazil and the relationship to offshore sedimentation. Geological Society, London, Special Publications, 153(1): 41-53.

Gallagher, K., Brown, R. \& Johnson, C. 1998. Fission track analysis and its applications to geological problems. Annual Review of Earth and Planetary Sciences, 26(1): 519-572.

Gallagher, K., Hawkesworth, C.J. \& Mantovani, M.S.M. 1994. The denudation history of the onshore continental margin of SE Brazil inferred from apatite fission track data. Journal of Geophysical Research, 99(B9): 18117-18145.

Gallagher, K., Hawkesworth, C.J. \& Mantovani, M.S.M. 1995. Denudation, fission track analysis and the long-term evolution of passive margin topography: application to the southeast Brazilian margin. Journal of South American Earth Sciences, 8(1): 65-77.

Genaro, D.T. 2008. Contribuição ao conhecimento de processos atuantes no rifteamento continental, por traços de fissão em zircões e apatitas, aplicados no rift continental do sudeste do Brasil, bacias de Taubaté, Resende, Volta Redonda e circunvizinhanças. Rio Claro, 131p. Dissertação de Mestrado, Programa de Pós-Graduação em Geociências e Meio Ambiente, Universidade Estadual Paulista.

Gilchrist, A.R. \& Summerfield, M.A. 1994. Tectonic models of passive margin evolution and their implications for theories of long-term landscape development. In: Kirkby, M.J. (Ed.). Process Models and Theoretical Geomorphology. Chichester, Wiley, p. 5584.

Gleadow, A.J.W. 1981. Fission-track dating methods: what are the real alternatives? Nuclear Tracks, 5: 3-14.

Godoy. D.F. 2003. História térmica e denudação do maciço alcalino de Poços de Caldas e circunvizinhanças: Área Norte. Rio Claro, 74p. Trabalho de Conclusão de Curso, Curso de Geologia, Instituto de Geociências e Ciências Exatas, Universidade Estadual Paulista.

Godoy, D.F. 2006. Termotectônica por traços de fissão em apatitas dos altos estrutrais de Pitanga, Pau d'Álho e Jibóia-centro do Estado de São Paulo. Rio Claro, 86p. Dissertação de Mestrado, Programa de Pós-Graduação em Geociências e Meio Ambiente, Universidade
Estadual Paulista.

Green, P.F. 1981. A new look at statistics in fission-track dating. Nuclear tracks, 5(1): 77-86.

Green, P.F. 1986. On the thermo-tectonic evolution of Northern England: evidence from fission track analysis. Geological Magazine, 123(5): 493-506.

Green, P.F., Duddy, I.R., Gleadow, A.J.W., Tingate, P.R. \& Laslett, G.M. 1986. Thermal annealing of fission tracks in apatite: 1. A qualitative description. Chemical Geology (Isotope Geoscience Section), 59: 237253.

Hackspacher, P.C., Godoy, D.F., Ribeiro, L.F.B., Neto, J.C.H. \& Franco, A.O.B. 2007. Modelagem térmica e geomorfologia da borda sul do Cráton do São Francisco: termocronologia por traços de fissão em apatita. Revista Brasileira de Geociências, 37(4): 76-86.

Hackspacher, P.C., Ribeiro, L.F.B., Ribeiro, M.C.S., Fetter, A.H., Hadler Neto, J.C., Tello Saenz, C.A. \& Dantas, E.L. 2004. Consolidation and break-up of the South American platform in Southeastern Brazil: tectonothermal and denudation histories. Gondwana Research, 7(1): 91-101.

Hadler, J.C., Paulo S.R., Iunes P.J., Tello Saenz C.A., Balestrieri M.L., Bigazzi G., Curvo E.A.C. \& Hackspacher P.C. 2001. A PC compatible Brazilian software for obtaining thermal histories using apatite fission track analysis. Radiation Measurements, 34:149-154.

Harman, R., Gallagher, K., Brown, R., Raza, A. \& Bizzi, L. 1998. Accelerated denudation and tectonic/geomorphic reactivation of the cratons of northeastern Brazil during the Late Cretaceous. Journal of Geophysical Research, 103(B11): 27091-27105.

Hiruma, S.T., Riccomini, C., Modenesi-Gauttieri, M.C., Hackspacher, P.C., Hadler Neto, J.C. \& Franco-Magalhaes, A.O.B. 2010. Denudation history of the Bocaina Plateau, Serra do Mar, southeastern Brazil: relationships to Gondwana breakup and passive margin development. Gondwana Research, 18: 674-687.

Japsen, P., Bonow, J.M., Green, P.F., Cobbold, P.R., Chiossi, D., Lilletveit, R., Magnavita, L.P. \& Pedreira, A. 2012. Episodic burial and exhumation in NE Brazil after opening of the South Atlantic. Geological Society of America Bulletin, 124: 800816.

Jelinek, A.R., Chemale, F., van der Beek, P.A., Guadagnin, F., Cupertino, J.A. \& Viana, A. 2014. Denudation history and landscape evolution of the northern East-Brazilian continental margin from apatite fission-track thermochronology. Journal of South American Earth Sciences, 54: 158-181.

Jelinek, A.R., Gomes, C.H., Dias, A.N.C., Guadagnin, F., Chemale Jr., F. \& Souza, I.A. 2010. Termocronologia aplicada às Geociências: análise por traços de fissão. Pesquisas em Geociências, 37 (3): 191-203.

Jelinek, A.R., Neto, A.C.B. \& Poupeau, G. 2003. Análise por traços de fissão em apatitas do Distrito Fluorítico de Santa Catarina: relações entre hidrotermalismo e evolução da margem continental. Brazilian Journal of Geology, 33(3): 289-298.

Karl, M., Glasmacher, U.A., Kollenz, S., Franco-Magalhaes, A.O., Stockli, D.F. \& Hackspacher, P.C. 2013. Evolution of the South Atlantic passive continental margin in 
southern Brazil derived from zircon and apatite (UTh-Sm)/He and fission-track data. Tectonophysics, 604: 224-244.

Laslett, G.M., Green, P.F., Duddy, I.R. \& Gleadow, A.J.W. 1987. Thermal annealing of fission tracks in apatite 2. A quantitative analysis. Chemical Geology: Isotope Geoscience Section, 65(1): 1-13.

Lima, M.V.A., Berrocal, J., Soares, J.E. \& Fuck, R.A. 2015. Deep seismic refraction experiment in northeast Brazil: New constraints for Borborema province evolution. Journal of South American Earth Sciences, 58: 335-349.

Macdonald, D., Gomez-Perez, I., Franzese, J., Spalletti, L., Lawver, L., Gahagan, L., Dalziel, I., Thomas, C., Trewin, N., Hole, M. \& Paton, D. 2003. Mesozoic break-up of SW Gondwana: implications for regional hydrocarbon potential of the southern South Atlantic. Marine and Petroleum Geology, 20(3): 287-308.

Meisling, K.E., Cobbold, P.R. \& Mount, V.S. 2001. Segmentation of an obliquely rifted margin, Campos and Santos basins, southeastern Brazil. AAPG Bulletin, 85(11): 1903-1924.

Milani, E.J. 1997. Evolução tectono-estratigráfica da Bacia do Paraná e seu relacionamento com a geodinâmica fanerozóica do Gondwana sul-ocidental. Porto Alegre, 255p. Tese de Doutorado, Programa de Pós-Graduação em Geociências, Instituto de Geociências, Universidade Federal do Rio Grande do Sul.

Mizusaki, A.M.P., Thomaz-Filho, A., Milani, E.J. \& Cesero, P. 2002. Mesozoic and Cenozoic igneous activity and its tectonic control in northeastern Brazil. Journal of South American Earth Sciences, 15 (2): 183-198.

Morais Neto, J.M., Green, P.F., Karner, G.D. \& Alkmim, F.F. 2008. Age of the Serra do Martins Formation, Borborema Plateau, northeastern Brazil: constraints from apatite and zircon fission track analysis. Boletim de Geociências da Petrobras, 16(1): 23-52.

Morais Neto, J.M., Hegarty, K.A., Karner, G.D. \& Alkmim, F.F. 2009. Timing and mechanisms for the generation and modification of the anomalous topography of the Borborema Province, northeastern Brazil. Marine and Petroleum Geology, 26: 1070-1086.

Naeser, C.W. \& Faul, H. 1969. Fission track annealing in apatite and sphene. Journal of Geophysical Research, 74(2): 705-710.

Neves, S.P. 2003. Proterozoic history of the Borborema province (NE Brazil): correlations with neighboring cratons and Pan-African belts and implications for the evolution of western Gondwana. Tectonics, 22: 1031.

Nürnberg, D. \& Müller, R.D. 1991. The tectonic evolution of the South Atlantic from Late Jurassic to present. Tectonophysics, 191: 27-53.

Oliveira, S.G., Hackspacher, P.C., Neto, J.C.H., Iunes, P.J., Paulo, S.R., Ribeiro, L.F.B. \& Saenz, C.A.T. 2000. Constraints on the evolution and thermal history of the continental platform of southeast Brazil, Sao Paulo state, using apatite fission track analysis (AFTA). Revista Brasileira de Geociências, 30(1): 107-109.

Oliveira, C.H.E., Jelinek, A.R., Chemale Jr., F. \& Bernet, M. 2016. Evidence of post-Gondwana breakup in South- ern Brazilian Shield: Insights from apatite and zircon fission track thermochronology. Tectonophysics, 666: 173-187.

Raab, M.J., Brown, R.W., Gallagher, K., Weber, K. \& Gleadow, A.J.W. 2005. Denudational and thermal history of the Early Cretaceous Brandberg and Okenyenya igneous complexes on Namibia's Atlantic passive margin. Tectonics, 24: TC3006.

Ribeiro, L.F.B. 2003. Morfotectônica da região centro-leste do estado de São Paulo e áreas adjacentes de Minas Gerais: Termocronologia \& Paleotensões. Rio Claro, 203p. Tese de Doutorado, Programa de Pós-Graduação em Geociências e Meio Ambiente, Instituto de Geociências e Ciências Exatas, Universidade Estadual Paulista.

Ribeiro, L.F.B., Hackspacher, P.C., Ribeiro, M.C.S., Hadler Neto, J.C., Tello Saenz, C.A., Iunes, P.J., Franco, A.B. \& Godoy, D.F. 2005. Thermotectonic and fault dynamic analysis of Precambrian basement and tectonic constraints within the Parana basin. Radiation Measurements, 39:669-673.

Ribeiro, M.C.S., Hackspacher, P.C., Ribeiro, L.F.B. \& Neto, J.C.H. 2011. Evolução tectônica e denudacional da Serra do Mar (SE/Brasil) no limite entre o Cretáceo Superior e Paleoceno, utilizando análises de traços de fissão e U-TH/HE em apatitas. Revista Brasileira de Geomorfologia, 12: 3-14.

Silva, J.S. 2010. Reconstrução termocronologica do maciço alcalino de Poços de Caldas e áreas adjacentes por traços de fissão e (U-Th-Sm) \he em apatitas e zircão. Rio Claro. Trabalho de Conclusão de Curso, Curso de Geologia, Instituto de Geociências e Ciências Exatas, Universidade Estadual Paulista.

Silva, L.G.A.E. 2006. A Interação entre os Eventos Tectônicos e a Evolução Geomorfológica da Serra da Bocaina, Sudeste do Brasil. Rio de Janeiro, 273p. Tese de Doutorado, Programa de Pós Graduação em Análise de Bacias e Faixas Móveis, Universidade do Estado do Rio de Janeiro.

Soares, C.J., Guedes, S., Jonckheere, R., Hadler, J.C., Passarella, S.M. \& Dias, A.N.C. 2015. Apatite fission-track analysis of Cretaceous alkaline rocks of Ponta Grossa and Alto Paranaíba Arches, Brazil. Geological Journal, 51: 805-810.

Souza, D.H., Hackspacher, P.C., Doranti-Tiritan, C. \& Godoy, D.F. 2014. Comparação da dinâmica evolutiva, em longo e curto prazo, entre o Planalto de Poços de Caldas e o Planalto de São Pedro de Caldas. Revista Brasileira de Geomorfologia, 16(2).

Tagami, T. \& O'Sullivan, P.B. 2005. Fundamentals of fission-track thermochronology. In: Reiners, P.W., Ehlers, T.A. (Ed.). Low-Temperature Thermochronology: Techniques, Interpretations, and Applications. Washington: Mineralogical Society of America, Reviews in Mineralogy and Geochemistry, v. 58, p. 1947

Tello Saenz, C., Hackspacher, P.C., Neto, J.H., Iunes, P.J., Guedes, S., Ribeiro, L.F.B. \& Paulo, S.R. 2003. Recognition of Cretaceous, Paleocene, and Neogene tectonic reactivation through apatite fission-track analysis in Precambrian areas of southeast Brazil: 
association with the opening of the South Atlantic Ocean. Journal of South American Earth Sciences, 15(7): 765-774.

Torsvik, T.H., Rousse, S., Labails, C. \& Smethurst, M.A. 2009. A new scheme for the opening of the South Atlantic Ocean and the dissection of an Aptian salt basin. Geophysical Journal International, 177(3): 1315-1333.

Turner, J.P., Green, P.F., Holford, S.P. \& Lawrence, S.R. 2008. Thermal history of the Rio Muni (West Africa) e NE Brazil margins during continental breakup. Earth and Planetary Science Letters, 270: 354-367.

Van Schmus, W.R., Kosuch, M. \& Brito Neves, B.B. 2011. Precambrian history of the Zona Transversal of the Borborema Province. Journal of South American

\section{Manuscrito 642}

Editores: Edinei Koester \& Maria do Carmo Lima e Cunha
Earth Sciences, 31: 227-252.

Wagner, G.A. \& Van den Haute, P. 1992. Fission-Track Dating. Dordrecht, Kluwer Academic Publishers, $285 \mathrm{p}$.

Zalán, P.V., Wolff, S., Astolfi, M.A.M., Vieira, I.S., Conceição, J.C.J., Appi, V.T., Santos Neto, E.V., Cerqueira, J.R. \& Marques, A. 1991. The Paraná Basin, Brazil. In: Leighton (Ed.). Interior Cratonic Basins. Memoir 51. AAPG, Tulsa, Oklahoma, p. 681-708.

Zalán, P.V., Wolff, S., Conceição, J.C., Marques, A., Astolfi, M.A.M., Vieira, I.S., Appi, V.T. \& Zanotto, O.A. 1990. Bacia do Paraná. In: Raja Gabaglia, G.P. \& Milani, E.J. (Eds.). Origem e Evolução de Bacias Sedimentares. Ed. Gávea, Petrobras, p.135-168. 